\title{
Atypical Chordoid Glioma of the Third Ventricle: A Case Report
}

\author{
Manash Bora $^{1} \quad$ R. S. Mittal ${ }^{1} \quad$ Amitesh Dubey $^{1} \quad$ S. Singhvi ${ }^{2}$ \\ ${ }^{1}$ Department of Neurosurgery, SMS Medical College, Jaipur, \\ Rajasthan, India \\ 2 Patho Care and Research Centre, Jaipur, Rajasthan, India \\ Address for correspondence Dr. Manash Bora, MS, Department of \\ Neurosurgery, SMS Medical College, Jaipur, Rajasthan, India \\ (e-mail: versatile11ghy@gmail.com).
}

Indian J Neurosurg 2015;4:124-127.

\begin{abstract}
Keywords

- chordoid glioma

- KI-67

- $\mathrm{p}^{53}$

- third ventricle

- immunohistochemistry (IHC)

Chordoid glioma of the third ventricle was classified as a rare tumor by the World Health Organization in 2000. Approximately 55 cases have been reported so far in world literature. These tumors are usually slow growing presenting with features of raised ICP. Most tumors have low proliferative index and these tumors are immunohistochemically negative for $\mathrm{P}^{53}$. We are reporting a case of chordoid glioma of the third ventricle, with atypical features of high proliferative index and $\mathrm{P}^{53}$ positivity on immunohistochemistry.
\end{abstract}

\section{Introduction}

Chordoid gliomas are unusual tumors that are found in the anterior third ventricle and are slow growing. Till now approximately 55 cases of chordoid gliomas of the third ventricle are reported in world literature. Magnetic resonance imaging (MRI) studies show isointense in $\mathrm{T}_{1} \mathrm{~W}$ and iso- to hyperintense tumor in $\mathrm{T}_{2} \mathrm{~W}$ with distinguished intense contrast enhancement and commonly hydrocephalus.

These tumors are not always amenable to complete resection due to attachment to the nearby important structures. ${ }^{1,2}$ Postoperative radiotherapy is advocated in residual tumors. ${ }^{1}$ Early as well as late recurrences are seen in cases of subtotal resection. ${ }^{1,2}$

\section{Case Report}

An 18-year-old man presented with attacks of severe bifrontal headache with vomiting for last 1 year. In the last 2 months, the severity and frequency of headache increased. Patient had transient loss of consciousness thrice in last 1 month. There was no history of seizure, endocrinopathies, or any other neurologic deficit. On admission patient was unconscious and had bilateral papilledema.

On computed tomography (CT) scan of the head ( - Fig. 1), there was a large homogenous hyperdense mass lesion in suprasellar region extending upward with enlargement of lateral ventricles. The third and fourth ventricles were not seen. Right ventriculoperitoneal (VP) shunt surgery was done on urgent basis. The patient's consciousness improved after shunt surgery. Pressure was high with clear cerebrospinal fluid (CSF) having much high CSF protein value $(1,500 \mathrm{mg} / \mathrm{dL})$.

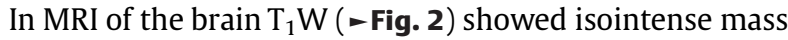
in the anterior third ventricle, which is hyperintense in $\mathrm{T}_{2} \mathrm{~W}$ and taking intense contrast enhancement (-Fig. 3).

Through anterior interhemispheric transcallosal approach, subtotal resection of tumor was done. Complete resection was not possible as the calcified part was densely adherent to hypothalamus.

On histopathologic examination there were polygonal cells with abundant eosinophilic cytoplasm arranged in groups. Cords and clusters of epithelioid cells embedded in mucinous matrix with focal lymphocytic infiltrate were seen (-Fig. 4). Immunohistochemistry showed vimentin and glial fibrillary acidic protein (GFAP) were strong positive (-Figs. 5 and 6). Diffuse membrane positivity for CD34, CD99, and epithelial membrane antigen (EMA) was present. $\mathrm{S}-100$ was positive in few cells. There was low $\mathrm{P}^{53}$ positivity (1-5\%). $\mathrm{K}_{\mathrm{i}}-67 / \mathrm{MIB}-1$ index was 7 to $15 \%$ (-Fig. 7). Overall morphology suggested chordoid glioma.
DOI http://dx.doi.org/ 10.1055/s-0035-1558838. ISSN 2277-954X. (c) 2015 Neurological Surgeons' Society of India
License terms

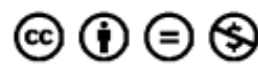

July 6, 2014

accepted

May 14, 2015

published online

July 28, 2015 


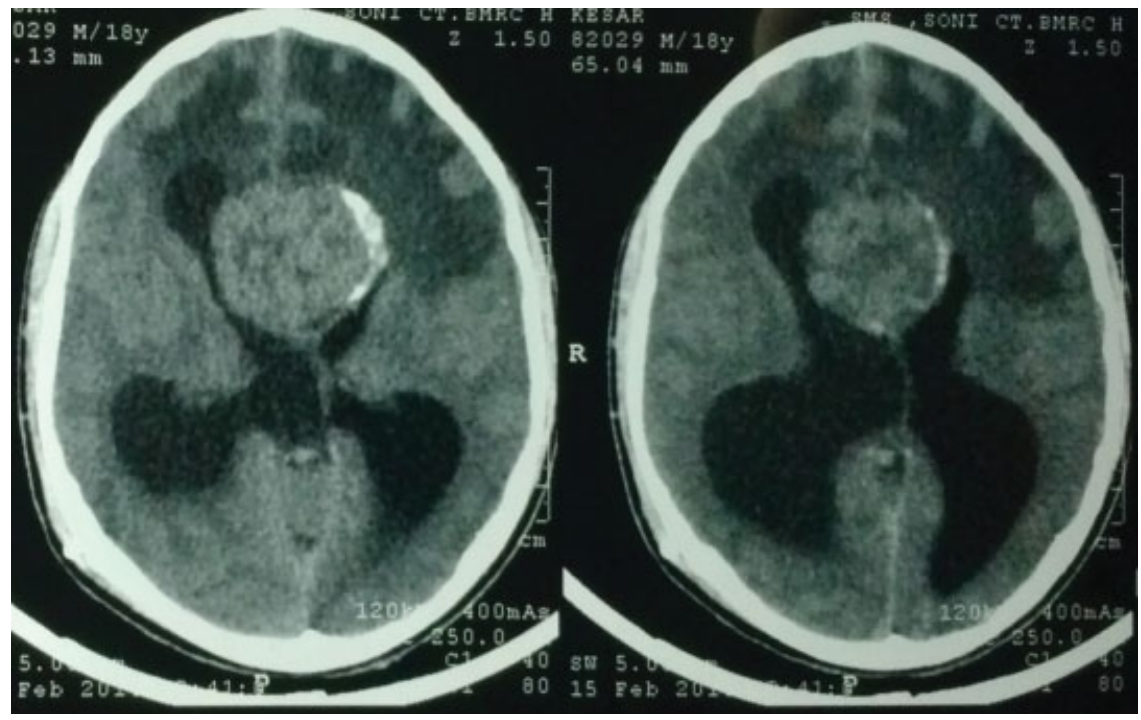

Fig. 1 Computed tomographic scan of the brain.

The patient was discharged without any complication and was given radiotherapy. At fifth month follow-up patient was asymptomatic. He was advised to get CT/MRI at regular intervals.

\section{Discussion}

After 1992, there were case reports with histopathologically confusing neoplasms arising in the anterior third ventricle. ${ }^{1,3-6}$ Histologic appearances of these tumors were of cords and clusters of epithelioid cells within a mucinous background along with a low-grade lymphoplasmacytic infiltrate. $^{1,2}$ Chordoma or chordoid meningiomas were

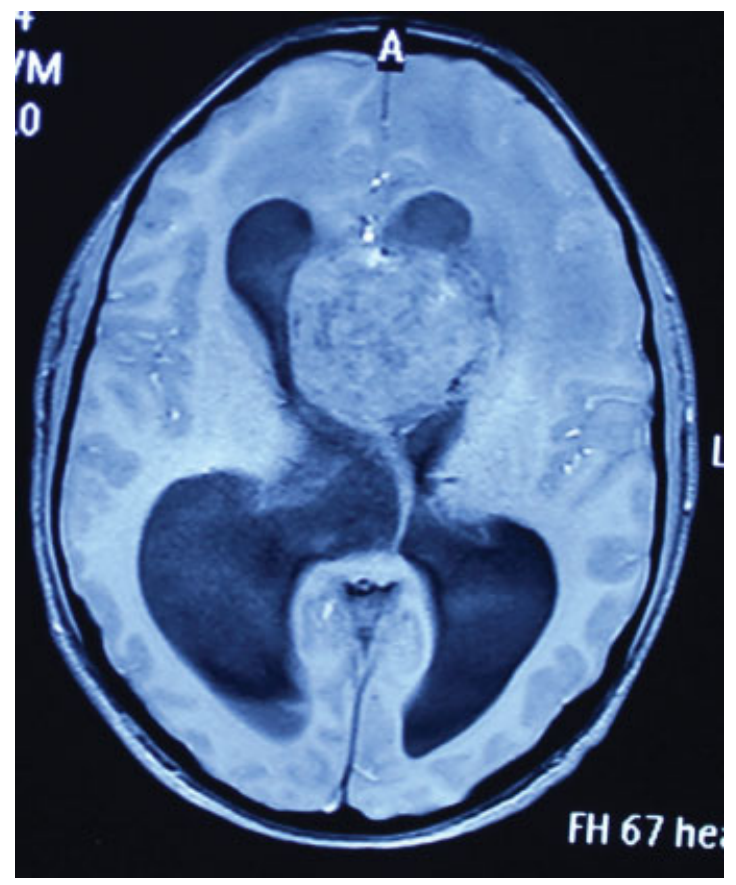

Fig. $2 \mathrm{~T}_{1} \mathrm{~W}$ magnetic resonance imaging of the brain. differential diagnoses, ${ }^{5}$ but unlike chordomas or chordoid meningiomas, these tumors stained avidly for GFAP. ${ }^{1}$ Therefore, this tumor did not conform to any existing glioma histopathologic classification system, leading Brat et $\mathrm{al}^{1,2,5,7}$ to propose that chordoid glioma was a separate pathologic entity. In 2000 WHO classified chordoid glioma as a distinct tumor type. ${ }^{1}$

Origin of chordoid glioma is not clear. There are hypotheses regarding ependymal or subependymal origin, hypothalamic origin, and embryonal origin because of midline tumor. ${ }^{1}$

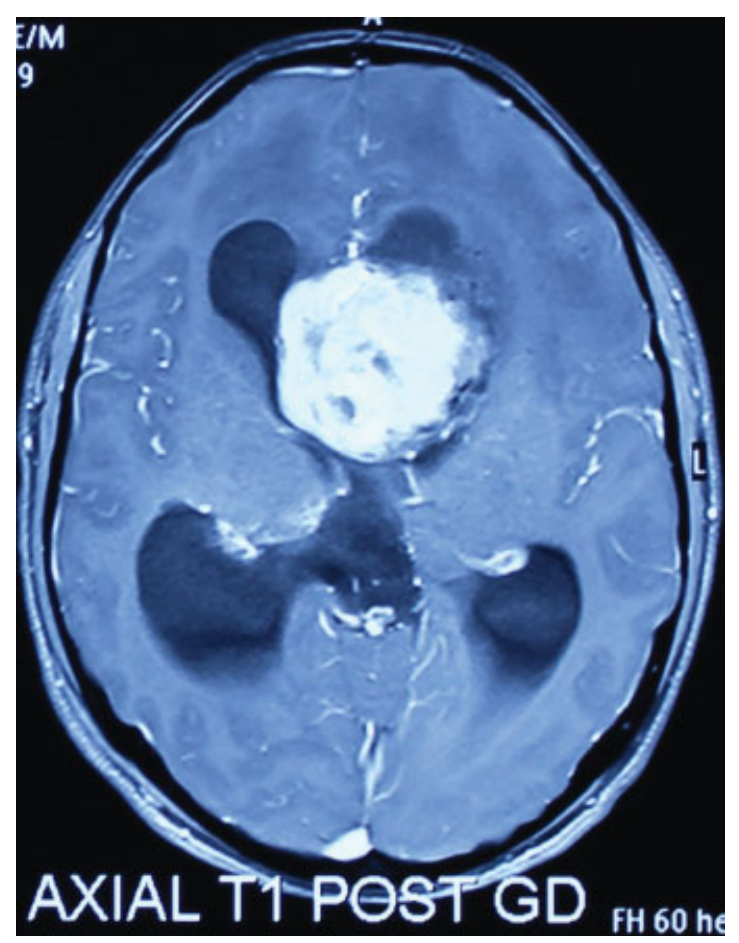

Fig. 3 Contrast-enhanced magnetic resonance imaging of the brain. 


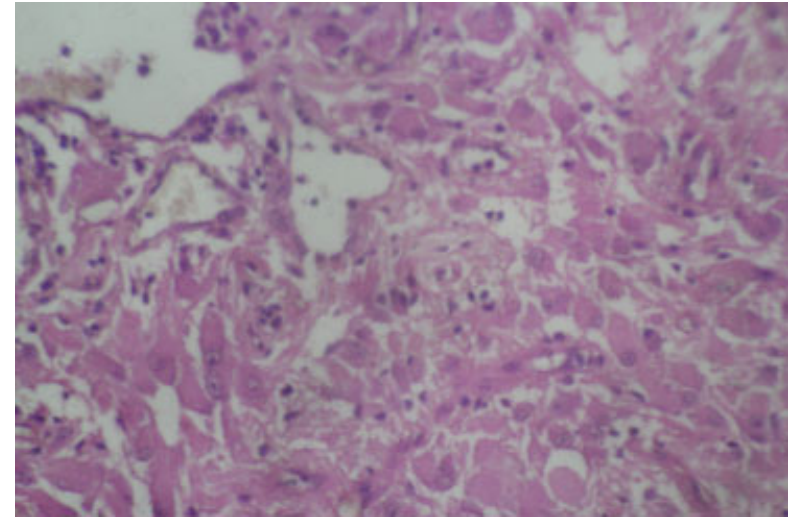

Fig. 4 Histopathology.

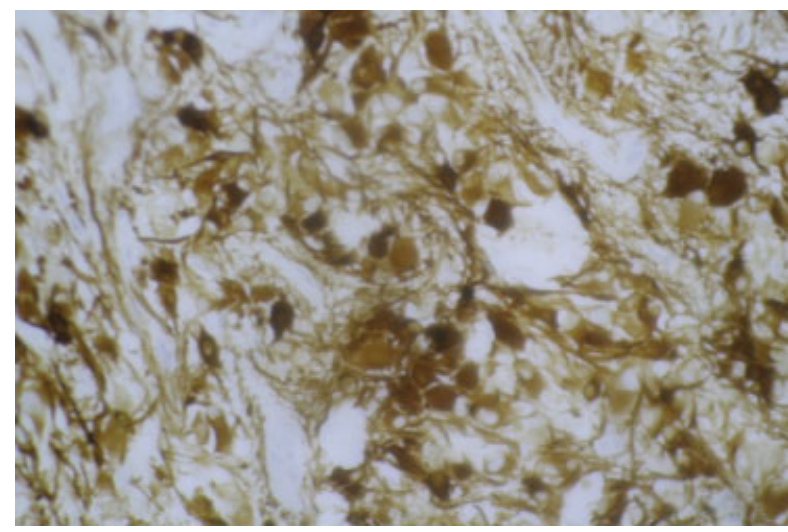

Fig. 5 Immunohistochemistry staining for glial fibrillary acidic protein positive.

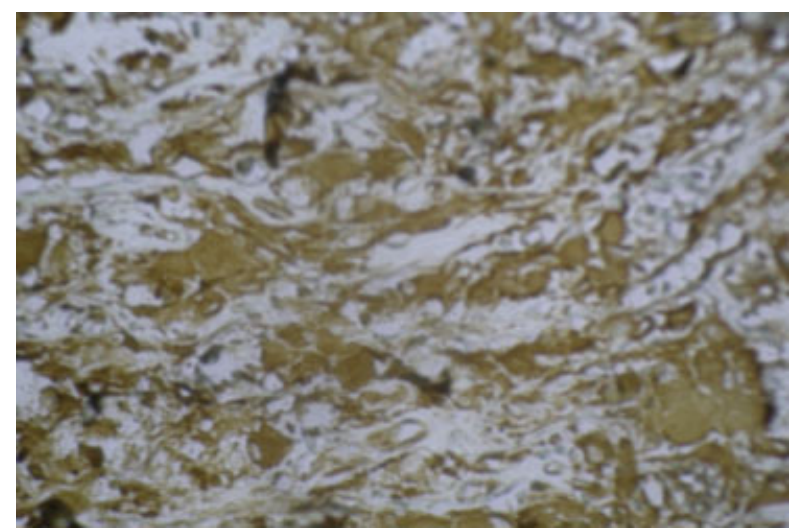

Fig. 6 Immunohistochemistry staining for vimentin positive.

Of the reported cases, most are young adults with symptoms of raised intracranial pressure (ICP). ${ }^{1}$ Our case also presented in same manner. Imaging was characteristic of chordoid glioma as reported earliar. ${ }^{1,2,8,9}$ As the tumor was attached to hypothalamus, total resection was not possible and subtotal

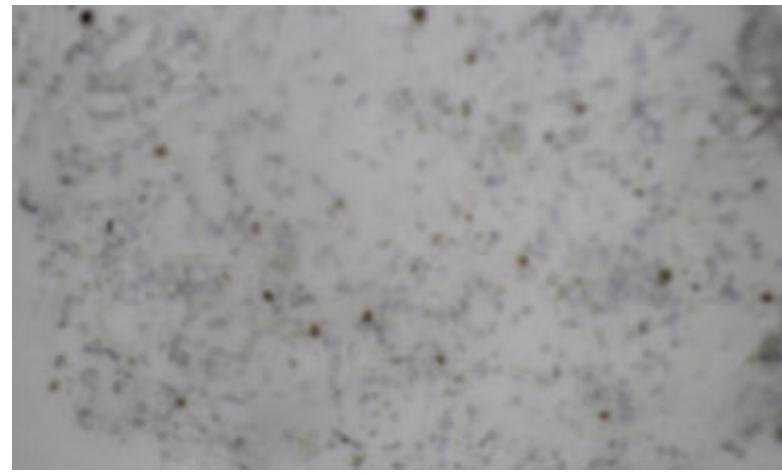

Fig. 7 Immunohistochemistry staining for KI-67/MIB-1.

resection was done. Biopsy and immunohistochemistry confirmed the tumor to be chordoid glioma (-Figs 4-6).

The unusual features noted in our case was that having high proliferative index, $\mathrm{KI}-67=7-15 \%$, but most reported cases had low proliferative index $(\mathrm{KI}-67<5 \%) .{ }^{10}$ Also, the tumor showed $\mathrm{P}^{53}$ positivity that was not observed in any previous reports. ${ }^{4,10}$ This suggests an aggressive lesion. There was also an associated aberrant expression of CD99 that indicates ependymal origin. The high CSF protein, with clear CSF and normal sugar and cells, points toward increased protein secreting nature of this tumor. No previous authors mentioned this CSF picture.

\section{Conclusion}

Chordoid glioma of the third ventricle is a distinct entity of low proliferative potential but may show high proliferative index with $\mathrm{P}^{53}$ positivity. These tumors may have protein secreting property.

\section{References}

1 Desouza RM, Bodi I, Thomas N, Marsh H, Crocker M. Chordoid glioma: ten years of a low-grade tumor with high morbidity. Skull Base 2010;20(2):125-138

2 Pomper MG, Passe TJ, Burger PC, Scheithauer BW, Brat DJ. Chordoid glioma: a neoplasm unique to the hypothalamus and anterior third ventricle. AJNR Am J Neuroradiol 2001;22(3):464-469

3 Vajtai I, Varga Z, Scheithauer BW, Bodosi M. Chordoid glioma of the third ventricle: confirmatory report of a new entity. Hum Pathol 1999;30(6):723-726

4 Reifenberger G, Weber T, Weber RG, et al. Chordoid glioma of the third ventricle: immunohistochemical and molecular genetic characterization of a novel tumor entity. Brain Pathol 1999;9(4): 617-626

5 Wanschitz J, Schmidbauer M, Maier H, Rössler K, Vorkapic P, Budka H. Suprasellar meningioma with expression of glial fibrillary acidic protein: a peculiar variant. Acta Neuropathol 1995;90(5):539-544

6 Brat DJ, Scheithauer BW, Staugaitis SM, Cortez SC, Brecher K, Burger PC. Third ventricular chordoid glioma: a distinct clinicopathologic entity. J Neuropathol Exp Neurol 1998;57(3):283-290 
7 Brat DJ, Scheithauer BW, Cortez SC, Reifenberger G, Burger PC. Chordoid glioma of the third ventricle. In: Kleihuis P, Cavenee WK, eds. Pathology and Genetics of Tumours of the Nervous System. 2nd ed. Lyon: International Agency for Research; 2000:90-91

8 Kendall B, Reider-Grosswasser I, Valentine A. Diagnosis of masses presenting within the ventricles on computed tomography. Neuroradiology 1983;25(1):11-22
9 Osborn AG. Brain tumors and tumor like masses: classification and differential diagnosis. In: Diagnostic Neuroradiology. Mosby; 1994:399-528

10 Sato K, Kubota T, Ishida M, Yoshida K, Takeuchi H, Handa Y. Immunohistochemical and ultrastructural study of chordoid glioma of the third ventricle: its tanycytic differentiation. Acta Neuropathol 2003;106(2):176-180 